\title{
The Efficacy of Self-Regulated Learning and Social Media in Higher Education
}

\author{
Budiharjo \\ Universitas Prof. Dr. Moestopo (Beragama) \\ Jl. Hang Lekir I No. 8, Senayan, Jakarta 10270 \\ budiharjo@dsn.moestopo.ac.id
}

\begin{abstract}
Self-regulated learning is a never-ending process in the life of a learner. This leads to areas such as learning analytics that concentrate on the learning trajectories of students while they interact with the learning environment. This research work highlights this intersection of self-regulated learning, social media in higher education to identify the ongoing themes and challenges in comprehending its efficacy in learning environments.
\end{abstract}

Keywords: Self-Regulated Learning; Personal Learning Environments; Social Media; Higher Education

\section{Introduction}

With the advent of the internet boom in early nineties to present, there has been a rapid proliferation of disruptive technologies in educational domain that have dramatically changed the teaching and learning landscape. This change has led to a widespread embracement of blended learning environments. Such advances in research pertaining specifically to educational technologies have redefined the educational landscape and have fostered an ecological paradigm that consists of interrelated variables involving the students, teachers, technologies, physical and virtual learning spaces [1].

Besides engaging into cognitive activity like learning strategy adaptability, prior knowledge also metacognitive processes like self-regulated strategies, self-efficacy and intrinsic motivation are some of the activities that students engage into in a blended learning environment [2-3]. Thus, to provide answers to a myriad number of factors that affect the quality of blended learning, the usage of self-regulated learning theory in educational paradigms serves to answer questions like why some students are better performers than others.

Learning Analytics and Educational Data Mining are two diverse research areas that serve to improve the quality of traditional brick and mortar classrooms and classrooms in the cloud (e-learning) by collecting massive datasets (to the tune of big data) on student learning activities in interacting with either the Leaning Management Systems (LMS) or Moodle or Blackboard or through user designed customized virtual private learning environments. From simple to complex algorithms are used to analyze the traces of digital imprints of student's interaction with the learning environment to help augment and improve the student's learning experience [4]. However, educational data analysis be it at a small scale or at the big data level have their own technological limitations that significantly lowers its potential [5]. In the absence of relevant educational framework that discusses the implication of SRL (Self-Regulated Learning) with social media can lead to uninterpretable results that are difficult to translate into meaningful pedagogical guidance. There are complex interactions that are intricated in a learning environment working on different factors. These interactions require a holistic approach for interpretability such that the student interactions with the learning environment can be merged with the theoretical underpinnings of the educational institution to improve 
context ability and reliability. This paper explores and analyzes the theoretical underpinnings of self-regulated learning feature of students in online environments.

The rest of this paper is organized as follows. Section 2 provides related work in areas of self-regulated learning and learning analytics are discussed. In Section 3, the usability of SRL at higher educational level is discussed. In Section 4, we have analyzed and discussed on the role of Personal Learning Environments (PLEs) in SRL. We conclude our discussion on this issue in Section 5 raising important questions requiring further research work.

\section{Related Works}

\subsection{Self-regulated Learning}

The student is described as self-regulated if it is metacognitively, motivationally and behaviorally active participants to its own learning processes, academic goals and perceptions of efficacy [6-7]. Self-regulation involves the usage of strategies to attain academic goals on the basis of self-efficacy perceptions. Moreover, self-regulated learning strategies are the actions that are posed at accessing relevant information or skill which requires the involvement of purpose, tools and instrumentality perceptions by the learners. These include methods like organizing and transforming information, seeking information, making notes and using memory aides [7]. In general there are three classes of strategies that are used for augmenting the regulatory personal influence of (self-) processes: strategies to control behavior, the environment and covert processes [8]

SRL is conceptually defined as the level of affinity by which the students are motivated at a metacognitive level to engage with their learning processes [7]. Although, there have been distinct perceptions in SRL that have laid emphasis on diverse elements in theoretical frameworks, e.g., $[9,10]$ all the theoretical models in SRL share the following four fundamental assumptions [11]. Foremost, the students serve to play a pivotal role in building meaning from their previous knowledge and their learning context. Secondly, the students have the skill to monitor and fine tune their own thinking and motivational levels. Moreover, the students have the intrinsic ability to modify their cognition and motivational levels to attain their learning goals. Lastly, SRL is driven by the interaction between student's learning adaptability characteristics and their learning contexts. Therefore, some pertinent questions have largely been unsolved in existing research on SRL. e.g. What are the elements that students use for aligning there learning needs with the content? How do they explore, select and adapt to tactical learning? How do they allocate time for subjects such as to maintain balance in learning? So although, selfreported data has provided intrinsic information on students ability to learning, but they have not measured how students employ learning tactics [12] or how the learning tactics are strategically employed to attain the learning objectives [13].

Although, the fundamental assumptions are common to all theoretical models of SRL, each model has its own distinct features. While, some models attribute, SRL as an eventbased activity, e.g. $[2,14]$ others perceive it as a progression through metacognitive monitoring and control [15-16]. In the same context, the model proposed by Winne [15] and Winne and Hadwin [17] upholds the information processing perspective, while the model proposed by McCaslin and Hickey [18] is rooted in the socio-cultural aspect. This research work has adopted Pintrich's social-cognitive perspective of SRL where the student's motivational, affective and cognitive processes are together affected by outlook towards external learning environment (like, classroom learning, e-learning) and internal environment (i.e. students thinking process) that may together belittle their learning outcomes $[11,19,20]$. In literature, SRL has been applied widely to determine the student's learning in computer-based learning (CBL) and hypermedia learning applicable to higher educational domain [21]. These studies have determined learner characteristics pertaining to student's SRL in CBL e.g. [10, 22, 23]; properties of the hypermedia 
learning tasks [24, 25] and how different learning instruments can be utilized for effective usage in SRL, e.g. [26-30].

This study focusses on learner characteristics in SRL, wherein we review studies that are empirical in nature in this area. In general, previous research has calibrated learner characteristics like earlier knowledge, ability, motivation and self-regulated strategy application, affects student SRL process and ability to obtain the learning outcomes in CBL. Specifically, the students who have demonstrated prior knowledge are inclined to preplan and monitor their learning better than students with less prior knowledge, e.g. [27]. High mark achieving students are far more likely to apply necessary learning strategies like notes taking during lectures or summarizing the lectures or inferential analysis of lectures as compared to students with low achieving marks [22]. The student's intrinsic motivational beliefs grounded in SRL, like self-efficacy and orientation towards goal achievement were found to directly proportional to academic success in CBL and hypermedia learning. In this reference the researchers, Joo, et al. [31] reported that student's performance in academic learning, internet usage for learning activities, web based learning was positively related to the learner's self-efficacy for SRL. The students with a higher level of learner control gained more in learning and outperformed the students with a lower level of learning control [32].

\subsection{Use of Learning Analytics in Education}

The inclusion of technology into education has witnessed a surge of data accumulation and needless to state these datasets are goldmine of nuggets of knowledge for both the researchers and data analysts. It has been shown that the data in combination with information retrieval technologies is a profitable prospect for both the emerging data economy and its use in education (Retalis et al., 2006; Johnson, et al., 2011). There are now various learning management systems (LMSs), intelligent tutoring systems, eportfolio systems and the personalized learning systems (PLEs) that are used in education and are generating vast amounts of logged data. Such rich datasets offer unexplored opportunities for the exploration of learning theories, learner feedback mechanism, learning technology and development of enhanced learning applications. This then paves the way for the importance of Learning Analytics (LA) which is gaining attention by governments, policy makers, educationists, research institutes and software vendors.

The early applications of LA were used to design systems known as Early Warning Systems [33, 34]. Dashboards containing visualizations on students were provided to instructors to augment learning [35-37], while some authors proposed the use of educational data for improving the learning designs [38], but the vast majority focused on predicting academic performance at various levels [39-42].

However, the usage of learner interaction data collected from the logs of interactive learning management systems is often times unable to provide a comprehensive perspective of a learning experience. Suthers and Verbert [43] proposed the requirement for a multivocal approach that collates the contribution of research in education, learning sciences and computer science to make informed learner decisions. Pardo, Ellis and Calvo [44] showed some preliminary work on the culminating self-reported and observed data where the learner outcomes necessitate further action.

\section{The Role of Social Media Usability in Higher Education}

The pervasive inclusion of social media and other Web 2.0 technologies is unprecedented [45]. Social media is now centerstage in learning and is an ingrained component of our life as users of the web2.0 technologies generate content, share pictures and choose to interact in online opinion polls. The ubiquities of social media are more apparent at a university where the technology is transforming the methods the students use to learn, communicate and collaborate. 
Social media, as a term defined as media that encompasses a conglomeration of networked technologies that emphasize upon the social aspects of the Internet as a medium for communication, collaboration and creative expression and this is often used as an interchangeable term with web 2.0 and social software [46]. A specific definition of this term might be elusive [47], social media (See Figure 1) is often described by example. Some examples of social media sharing tools are WordPress, Pinetrest, Delicious that are precursors to online social blogging, microblogging; wiki software like PBworks that serves as creation of collaboration spaces, media sharing tools like Instagram, Flickr and Youtube that integrated social tagging and Social Networking Sites (SNSs) like Facebook, LinkedIn; including others like cloud based office sharing tools like Google Apps that enable document and calendar sharing resources [48, 49]. While some researchers $[47,50,51]$ use the term Web 2.0 when referring to SNSs and other social media. Yet in another study it was reported that the College-users (Facebook's most mature market) "spent 25\% less time on the site as in August 2012, a declining trend that is predicted to continue" [52].

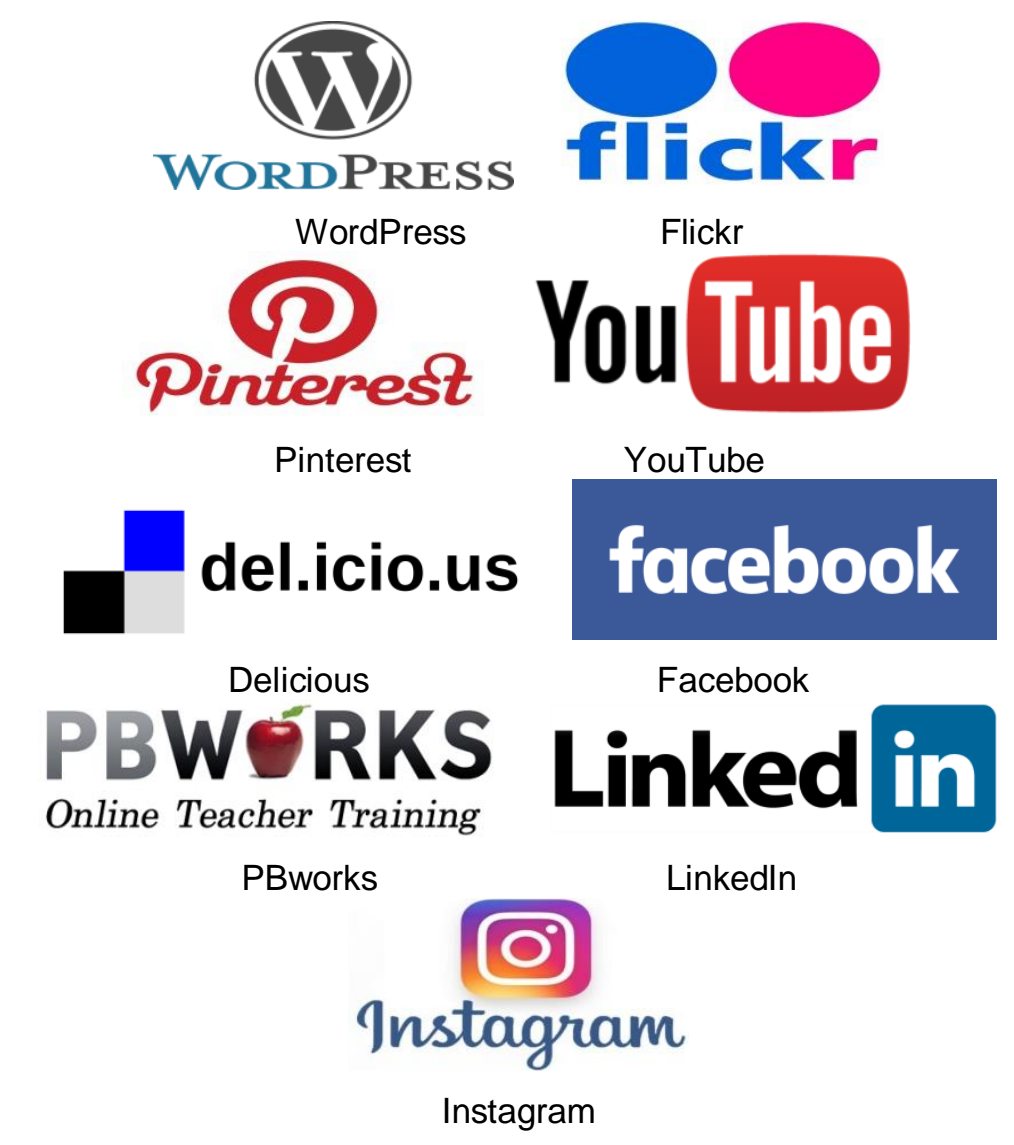

Figure 1. Social Media (Source from the Internet)

\subsection{Facebook in Education}

Facebook was developed in 2004 by the then Harvard undergraduate Mark Zuckerberg, and is among the "dominant" social networking site [45]. There have been several studies that have reported the statistics on Facebook usage and its adoption [53-56], the research work conducted by Ellison, Steinfield, and Lampe [57] has revealed that, "94\% of their college students were Facebook users spending a daily average of 10-30 mins on the website with more than 100-200 friends". In another study, it was found that "90\% of undergraduate students were reported to own Facebook accounts" [58]. 
The researchers [59] studied the use of Facebook pages in four specific university courses. Based on student's SRL perceptions, the findings reveal that most of the course participants," $(N=135,78 \%)$ " initially felt that Facebook can be an effective learning tool. However, in the post course surveys, only " $50 \%$ " of the students felt that the inclusion of Facebook actually assisted them in their learning. To this the researchers attribute the reason to be the instructor's inconsistency in integration of Facebook. Another group of researchers [60] reported similar findings on student's perception of using Facebook for learning medium. They conducted a survey in a biology course where the student's, " $(N=100)$ ", felt that communication with other students " $(95.5 \%)$ ", access to notes and materials "(86.3\%)", and schedule views "(82.8\%)" were the likely outcomes. It was also found that online discussion with the instructor was only "64.3\%" and general communication with the instructor was lesser to " $56.4 \%$ ".

\subsection{MySpace in Education}

An early precursor to SNSs was MySpace that was co-founded by Chris DeWolfe and Tom Anderson in 2003. With an unprecedented growth in few years it was considered the leading social media site [45]. The users of this SNS were generally women with varied ethnicities and having high school to college level education. The median age was 27 years old. It was reported that "fifty percent of adult SNSs users owned a MySpace account". Like Facebook, it also offers an integrated platform for communication, audio/video media sharing and creating connections [61].

\subsection{Twitter in Education}

In an experimental study to measure the effects of social media on student engagement and achievement [62] analyzed the differences in the mean student engagement scores (from the National Survey of Student Engagement) and average semester GPA across student groups. The sample size was "125 pre-health majors (70 students in the experimental group)" that used Twitter for "educationally relevant activities" (e.g., classroom discussions, class reminders, book discussions and conversations). It was found that there were significant changes in student engagement scores in the Twitter sections " $(p<0.18)$ ". The semester GPA was also "significantly better for Twitter group $(p=0.037)$ ". Another group of researcher's [63], integrated Twitter into an online instructional design and technology course. They did this so as to move beyond the scope of using the conventional Course Management Systems (CMSs) and the researchers indicated the benefits of Twitter over CMSs as being able to address user issues on time, help the students in writing concisely. It also supported informal learning and helped the user to write with specificity. The researchers also indicated the possible drawbacks of Twitter use in educational context included time management, addiction and bad grammar encouragement due to the character limit of the tweets.

\section{The Role of Personal Learning Environment's (PLEs) in SRL}

In general, SRL is perceived more as a skill using which students learn to plan and set their learning goals, strategies to obtain on how to attain these goals and self-retrospection on goal achievements. Therefore, for the students to achieve their personalized learning goals they must be self-driven by passion and dreams to achieve their targets [49]. The motivational component in SRL drives the student to persist to their goals in face of adverse situation.

The three-phase cyclic SRL model proposed by Zimmerman [64] is an attempt to explain the process behind student's academic achievement. In this model the primary phase is termed as the forethought phase, where the student has a predefined cognition of thoughts and approaches like focused target setting and planning or self-beliefs (e.g., task 
interest, self-efficacy) on how to handle or tackle the learning task. For example, a student who believes that he is weak in statistics will report a loss of interest in it and would experience that statistics is not important to him/her and will be less likely to excel in statistics or will demonstrate a lack of persistence to continue learning the subject. In the secondary phase, the performance phase, the student initiates to engage in behaviors that are instrumental to him/her attaining the learning goals. In the tertiary and the last phase of the model, which is the self-reflection phase, the student begins to apply his/her innate judgement to analyze their learning performance. The choice the student makes in the secondary and tertiary phases, constitute the self-evaluative judgements that pave the way for future course of actions that are related to the primary phase of the model; the forethought phase. Thus, we can say that SRL are engaged in a constant cyclic feedback loop until they have successfully achieved their goals.

Although, there have been several studies that have implemented Zimmerman's three phase model to asses and quantify self-regulation learning in online and blended learning environments [49]; it is noteworthy to point that less research work has been performed that explores the relationship between self-regulation and social presence fundamental to PLEs. The researchers, $[65,66]$ have studied the engagement levels of college students in an online learning environment and have assessed their SRL behavior in such as setting where the entire course was delivered completely in an online mode. It was found in this study that the students perceived instructor and peer presence as an ability to, "project oneself to others emotionally and socially" (p. 299) and the student's perception towards social presence was designated as students feeling of belongingness to the community. The results in this study have shown that SRL can be instrumental in predicting the peer and instructor presence in social communities. It can also help in predicting the ratio of community connectedness and peer co-alliances.

Moreover, [65] have shown that the connection between SRL and social media are used by the learner and have argued that "organizing learning resources available at a PLE into meaningful learning activities towards achieving set goals can as well be considered as an act of instructional design" (p. 4), and that this "act" is directly proportional to the primary phase of Zimmerman's three phase cyclic SRL model. It has also been suggested by [67] that the integration of social media by the learner helps to facilitate three social cognitive processes: information, identity and relationship analysis and management. These processes culminate in self-representation grounded on psychological needs such as competence (preceptor self-efficacy), relatedness (sense of being part of a process) and acceptance (social approval) that together are acts of self-regulated learning [65]. The researchers [49] carried forward the earlier works to develop a pedagogical framework for social media use that directly aligns with the three phases of the Zimmerman's model.

\subsection{Discussion}

Social media has played a pivotal role in augmenting almost every aspect of human life including education, politics or sports [68]. It has emerged as a powerful tool that exercises great strength in nurturing and building the area it impacts. Education, is no exception to the pervasive inclusion of social media in it either [69]. So, while, most universities and colleges have adopted the inclusion of social media as part of their infrastructure, the users of it (instructors) are at a slower pace in using it to its maximum potential. Studies such as [70-71] have shown the inclusion and usage of social media between course structure and social networking sites. The most debatable question posed by both the educators and policy makers is, what is the efficacy of social media in higher education? A decade ago, social media was considered to exercise greater control in social circles but with the advent of disruptive technologies encroaching into social media the boundary lines are blurred. In fact, social media has made its way right in a university campus, however recently its effectiveness to disseminate educational content has been considered a potent solution by most educators. There have been a several studies on 
social media from an instructor's perspective but fewer to negligible research works exist from an institutional or policy maker's perspective. Therefore, it is important that we consider a broader outlook on this issue and realize its potential benefits or misgivings in the educational context.

Future research on SRL that serves to promote effective learning by the student must also solve challenges that are presented by often probable and persistent objective that learning is social. Any attempt to bypass this challenge is to solicit the abstractions amongst learners being similar to classroom based learning [72]. We therefore, surmise a bridging point between the social context of learning to that of active learning which the learner applies in a SRL environment. Several challenges that are faced by learning analysts share similarities with researchers in the domain of data mining [73-80].

\section{Conclusion}

Social media has played an important role in augmenting almost every aspect of human life including education. This work has successfully highlighted the intersection of selfregulated learning, social media in higher education to identify the ongoing themes and challenges in comprehending its efficacy in learning environments. For future research, by tight coupling between SRL, learning analytics and data mining, evidently several communities stand to benefit. Thus, at a holistic perspective, the intersection of SRL and social media in education offers a grand challenge with a great impact on various stakeholders like student, teacher, policy maker and government policies.

\section{Acknowledgement}

This research is supported by Universitas Prof. Dr. Moestopo (Beragama), Indonesia.

\section{References}

[1] R. Ellis and P. Goodyear, Students' experiences of e-learning in higher education: the ecology of sustainable innovation: Routledge, 2013.

[2] R. Azevedo, D. C. Moos, A. M. Johnson, and A. D. Chauncey, "Measuring cognitive and metacognitive regulatory processes during hypermedia learning: Issues and challenges," Educational Psychologist, vol. 45, pp. 210-223, 2010.

[3] R. Azevedo, "Theoretical, conceptual, methodological, and instructional issues in research on metacognition and self-regulated learning: A discussion," Metacognition and Learning, vol. 4, pp. 87-95, 2009.

[4] R. S. Baker and P. S. Inventado, "Educational data mining and learning analytics," in Learning analytics, ed: Springer, 2014, pp. 61-75.

[5] S. Knight, S. Buckingham Shum, and K. Littleton, "Epistemology, assessment, pedagogy: where learning meets analytics in the middle space," Journal of Learning Analytics, vol. 1, pp. 23-47, 2014.

[6] B. J. Zimmerman, "Development of self-regulated learning: Which are the key subprocesses," Contemporary Educational Psychology, vol. 16, pp. 307-313, 1986.

[7] B. J. Zimmerman, "A social cognitive view of self-regulated academic learning," Journal of educational psychology, vol. 81, p. 329, 1989.

[8] R. F. Baumeister, T. F. Heatherton, and D. M. Tice, Losing control: How and why people fail at selfregulation: Academic press, 1994.

[9] B. J. Zimmerman and D. H. Schunk, Self-regulated learning and academic achievement: Theoretical perspectives: Routledge, 2001.

[10] D. C. Moos and C. A. Stewart, "Self-regulated learning with hypermedia: Bringing motivation into the conversation," in International handbook of metacognition and learning technologies, ed: Springer, 2013, pp. 683-695.

[11] P. R. Pintrich, The role of goal orientation in self-regulated learning. San Diego,CA, US: Academic Press, 2000.

[12] P. H. Winne and D. Jamieson-Noel, "Exploring students' calibration of self reports about study tactics and achievement," Contemporary Educational Psychology, vol. 27, pp. 551-572, 2002.

[13] A. F. Hadwin, P. H. Winne, D. B. Stockley, J. C. Nesbit, and C. Woszczyna, "Context moderates students' self-reports about how they study," Journal of Educational Psychology, vol. 93, p. 477, 2001. 
[14] J. A. Greene and R. Azevedo, "The measurement of learners' self-regulated cognitive and metacognitive processes while using computer-based learning environments," Educational psychologist, vol. 45, pp. 203-209, 2010.

[15] P. H. Winne, "Self-regulated learning viewed from models of information processing," Self-regulated learning and academic achievement: Theoretical perspectives, vol. 2, pp. 153-189, 2001.

[16] P. H. Winne and N. E. Perry, "Measuring self-regulated learning," 2000.

[17] P. H. Winne and A. F. Hadwin, "Studying as self-regulated learning," Metacognition in educational theory and practice, vol. 93, pp. 27-30, 1998.

[18] M. McCaslin and D. T. Hickey, "Educational psychology, social constructivism, and educational practice: A case of emergent identity," Educational Psychologist, vol. 36, pp. 133-140, 2001.

[19] P. R. Pintrich and E. V. De Groot, "Motivational and self-regulated learning components of classroom academic performance," Journal of educational psychology, vol. 82, p. 33, 1990.

[20] P. R. Pintrich, C. A. Wolters, and G. P. Baxter, "2. Assessing Metacognition and Self-Regulated Learning," 2000.

[21] F. I. Winters, J. A. Greene, and C. M. Costich, "Self-regulation of learning within computer-based learning environments: A critical analysis," Educational Psychology Review, vol. 20, pp. 429-444, 2008.

[22] R. Azevedo, J. T. Guthrie, and D. Seibert, "The role of self-regulated learning in fostering students' conceptual understanding of complex systems with hypermedia," Journal of Educational Computing Research, vol. 30, pp. 87-111, 2004.

[23] P. E. Williams and C. M. Hellman, "Differences in self-regulation for online learning between first-and second-generation college students," Research in Higher Education, vol. 45, pp. 71-82, 2004.

[24] D. H. Schunk and P. A. Ertmer, "Self-regulatory processes during computer skill acquisition: Goal and self-evaluative influences," Journal of Educational Psychology, vol. 91, p. 251, 1999.

[25] G. Stahl, T. Koschmann, and D. Suthers, "Computer-supported collaborative learning: An historical perspective," Cambridge handbook of the learning sciences, vol. 2006, pp. 409-426, 2006.

[26] S. P. Lajoie, L. Naismith, E. Poitras, Y.-J. Hong, I. Cruz-Panesso, J. Ranellucci, "Technology-rich tools to support self-regulated learning and performance in medicine," in International handbook of metacognition and learning technologies, ed: Springer, 2013, pp. 229-242.

[27] D. C. Moos and R. Azevedo, "Self-regulated learning with hypermedia: The role of prior domain knowledge," Contemporary Educational Psychology, vol. 33, pp. 270-298, 2008.

[28] S. Narciss, A. Proske, and H. Koerndle, "Promoting self-regulated learning in web-based learning environments," Computers in Human Behavior, vol. 23, pp. 1126-1144, 2007.

[29] A. Proske, S. Narciss, and H. Körndle, "Interactivity and learners' achievement in web-based learning," Journal of Interactive Learning Research, vol. 18, p. 511, 2007.

[30] V. Venkatesh, K. Shaikh, A. Zuberi, K. Urbaniak, T. Gallant, and A. Lakhana, "Development of Task Understanding and Monitoring in Information Retrieval Environments: Demystifying Metacognitive and Self-Regulatory Mechanisms in Graduate Learners Using Topic Maps Indexing Technologies to Improve Essay-Writing Skills," in International Handbook of Metacognition and Learning Technologies, ed: Springer, 2013, pp. 277-291.

[31] Y.-J. Joo, M. Bong, and H.-J. Choi, "Self-efficacy for self-regulated learning, academic self-efficacy, and Internet self-efficacy in Web-based instruction," Educational Technology Research and Development, vol. 48, pp. 5-17, 2000.

[32] W. Eom and R. A. Reiser, "The effects of self-regulation and instructional control on performance and motivation in computer-based instruction," International Journal of Instructional Media, vol. 27, p. 247, 2000.

[33] A. E. Krumm, R. J. Waddington, S. D. Teasley, and S. Lonn, "A learning management system-based early warning system for academic advising in undergraduate engineering," in Learning Analytics, ed: Springer, 2014, pp. 103-119.

[34] S. Lonn, A. E. Krumm, R. J. Waddington, and S. D. Teasley, "Bridging the gap from knowledge to action: Putting analytics in the hands of academic advisors," in Proceedings of the 2nd International Conference on Learning Analytics and Knowledge, 2012, pp. 184-187.

[35] L. Corrin and P. de Barba, "Exploring students' interpretation of feedback delivered through learning analytics dashboards," in Proceedings of the ascilite 2014 conference, 2014.

[36] K. Verbert, S. Govaerts, E. Duval, J. L. Santos, F. Van Assche, G. Parra, "Learning dashboards: an overview and future research opportunities," Personal and Ubiquitous Computing, vol. 18, pp. 1499$1514,2014$.

[37] D. Verpoorten, W. Westera, and M. Specht, "A first approach to "Learning Dashboards" in formal learning contexts," 2011.

[38] L. Lockyer, E. Heathcote, and S. Dawson, "Informing pedagogical action: Aligning learning analytics with learning design," American Behavioral Scientist, p. 0002764213479367, 2013.

[39] C. Antunes, Anticipating student's failure as soon as possible: Chapman \& Hall/CRC Press, New York, NY, 2010.

[40] C. Romero, M. I. López, J. M. Luna, and S. Ventura, "Predicting students' final performance from participation in on-line discussion forums," Computers \& Education, vol. 68, pp. 458-472, 2013. 
[41] A. Essa and H. Ayad, "Student success system: risk analytics and data visualization using ensembles of predictive models," in Proceedings of the 2nd international conference on learning analytics and knowledge, 2012, pp. 158-161.

[42] A. Essa and H. Ayad, "Improving student success using predictive models and data visualisations," Research in Learning Technology, vol. 20, 2012.

[43] D. Suthers and K. Verbert, "Learning analytics as a middle space," in Proceedings of the Third International Conference on Learning Analytics and Knowledge, 2013, pp. 1-4.

[44] A. Pardo, R. A. Ellis, and R. A. Calvo, "Combining observational and experiential data to inform the redesign of learning activities," in Proceedings of the Fifth International Conference on Learning Analytics And Knowledge, 2015, pp. 305-309.

[45] A. Lenhart, K. Purcell, A. Smith, and K. Zickuhr, "Social Media \& Mobile Internet Use among Teens and Young Adults. Millennials," Pew internet \& American life project, 2010.

[46] T. Joosten, Social media for educators: Strategies and best practices: John Wiley \& Sons, 2012.

[47] A. M. Kaplan and M. Haenlein, "Users of the world, unite! The challenges and opportunities of Social Media," Business horizons, vol. 53, pp. 59-68, 2010.

[48] N. Dabbagh and R. Reo, "Impact of Web 2.0 on higher education," Technology integration in higher education: Social and organizational aspects, pp. 174-187, 2010.

[49] A. Kitsantas and N. Dabbagh, Learning to learn with Integrative Learning Technologies (ILT): A practical guide for academic success. Greenwich: CT:Information Age Publishing., 2010.

[50] A. Gruzd, K. Staves, and A. Wilk, "Tenure and promotion in the age of online social media," Proceedings of the American Society for Information Science and Technology, vol. 48, pp. 1-9, 2011.

[51] A. Hemmi, S. Bayne, and R. Land, "The appropriation and repurposing of social technologies in higher education," Journal of computer assisted learning, vol. 25, pp. 19-30, 2009.

[52] H. Blodget, "ANALYST: Facebook has a big new problem you need to worry about," Business insider, September 12, 2012.

[53] E. Hargittai, "Whose space? Differences among users and non-users of social network sites," Journal of Computer-Mediated Communication, vol. 13, pp. 276-297, 2007.

[54] S. Jones and S. Fox, "Generations online in 2009. Washington DC: Pew Internet \& American Life Project," ed, 2009.

[55] A. Lenhart and M. Madden, "Teens, privacy and online social networks: How teens manage their online identities and personal information in the age of MySpace," 2007.

[56] G. Salaway and J. Caruso, "The ecar study of undergraduate students and information technology, 2007 key findings," 2008.

[57] N. B. Ellison, C. Steinfield, and C. Lampe, "The benefits of Facebook "friends:" Social capital and college students' use of online social network sites," Journal of Computer-Mediated Communication, vol. 12, pp. 1143-1168, 2007.

[58] K. F. Hew, "Students' and teachers' use of Facebook," Computers in Human Behavior, vol. 27, pp. 662 676, 2011.

[59] C. Irwin, L. Ball, B. Desbrow, and M. Leveritt, "Students' perceptions of using Facebook as an interactive learning resource at university," Australasian Journal of Educational Technology, vol. 28, pp. 1221-1232, 2012.

[60] J. D. Ophus and J. T. Abbitt, "Exploring the potential and perceptions of social networking systems in university courses," Journal of Online Learning and Teaching, vol. 5, p. 639, 2009.

[61] D. Boyd and N. Ellison, "Social network sites: definition, history, and scholarship," IEEE Engineering Management Review, vol. 3, pp. 16-31, 2010.

[62] R. Junco, G. Heiberger, and E. Loken, "The effect of Twitter on college student engagement and grades," Journal of Computer Assisted Learning, vol. 27, pp. 119-132, 2011.

J. C. Dunlap and P. R. Lowenthal, "Tweeting the night away: Using Twitter to enhance social presence," Journal of Information Systems Education, vol. 20, p. 129, 2009.

[63] B. J. Zimmerman, M. Boekarts, P. Pintrich, and M. Zeidner, "Attainment of self-regulation: A social cognitive perspective," Self-regulation: Theory, research, and applications, vol. 13, pp. 13-39, 2000.

[64] M. A. Türker and S. Zingel, "Formative interfaces for scaffolding self-regulated learning in PLEs," elearning Papers, vol. 14, 2008.

[65] M.-H. Cho, S. Demei, and J. Laffey, "Relationships between self-regulation and social experiences in asynchronous online learning environments," Journal of Interactive Learning Research, vol. 21, p. 297, 2010.

[66] J. Schmidt, Social software: Facilitating information-, identity-and relationship management. Norderstedt, Germany: T. N. Burg, \& J. Schmidt (Eds.), 2006.

[67] J.H. Abawajy, M.I.H. Ninggal, and T. Herawan. Privacy Preserving Social Network Data Publication and Analysis. IEEE Communication, Survey and Tutorials, Issue 99, DOI 10.1109/COMST.2016.2533668.

[68] H. Chiroma, AI Abu Bakar. N. Mohd Shuib, T. Herawan, \& J.H. Abawajy. Advances in Teaching and Learning on Facebook in Higher Institutions. IEEE Access, DOI: 10.1109/ACCESS.2016.2643682, 2016. 
[69] S. Bennett, A. Bishop, B. Dalgarno, J. Waycott, and G. Kennedy, "Implementing Web 2.0 technologies in higher education: A collective case study," Computers \& Education, vol. 59, pp. 524-534, 2012.

[70] A. Dutt, M.A. Ismail, and T. Herawan. A Systematic Review on Educational Data Mining. IEEE Access, December 2016.

[71] Budiharjo. Integrated Quality Management-based Education in Indonesia. International Journal on Advanced Science, Engineering and Information Technology, 6(5), 746-756, 2016.

[72] P. H. Winne and R. S. Baker, "The potentials of educational data mining for researching metacognition, motivation and self-regulated learning," JEDM-Journal of Educational Data Mining, vol. 5, pp. 1-8, 201

[73] Herawan, T., Vitasari, P. and Abdullah, Z., 2013. Mining critical least association rules of student suffering language and social anxieties. International Journal of Continuing Engineering Education and Life Long Learning 2nd, 23(2), pp.128-146.

[74] Suhirman, S., Herawan, T., Chiroma, H. and Mohamad Zain, J., 2014. Data Mining for Education Decision Support: A Review. International Journal of Emerging Technologies in Learning (iJET), 9(6), pp.4-19.

[75] Zailani, A., Herawan, T., Noraziah, A. and Mustafa, M.D., 2014. Mining Least Association Rules of Degree Level Programs Selected by Students. International Journal of Multimedia and Ubiquitous Engineering (IJMUE), 9(1), pp.241-254.

[76] S.R. Aghabozorgi, H. Mahroeian, A. Dutt, Teh Y.W., and T. Herawan. An Approachable Analytical Study on Big Educational Data Mining. In B. Murgante (Eds.): ICCSA 2014, Lecture Notes in Computer Science, Volume 8583, pp. 721-737. (C) Springer-Verlag 2014.

[77] Suhirman, Herawan, T., Yanto, I.T.R., Zain, J.M., Hongwu, Q. and Abdullah, Z., 2015. A Soft Set Approach for Clustering Student Assessment Datasets. Journal of Computational and Theoretical Nanoscience, 12(12), pp.5928-5939.

[78] Herawan, T., Chiroma, H., Vitasari, P., Abdullah, Z., Ismail, M.A. and Othman, M.K., 2015. Mining critical least association rules from students suffering study anxiety datasets. Quality \& Quantity, 49(6), pp.2527-2547.

[79] Novitasari, W., Hermawan, A., Abdullah, Z., Sembiring, R.W. and Herawan, T., 2015. A Method of Discovering Interesting Association Rules from Student Admission Dataset. International Journal of Software Engineering and Its Applications, 9(8), pp.51-66. 